\title{
Analysis of a Prophage Gene Frequency Revealed Population Variation of 'Candidatus Liberibacter asiaticus' from Two Citrus-Growing Provinces in China
}

Rui Liu, Pei Zhang, Xuelian Pu, and Xiaoqian Xing, Laboratory of Huanglongbing Research, Department of Plant Pathology, South China Agricultural University, Guangzhou, Guangdong, P.R. China; Jianchi Chen, Crop Diseases, Pests and Genetics Research, San Joaquin Valley Agricultural Sciences Center, United States Department of Agriculture, Parlier, CA; and Xiaoling Deng, Laboratory of Huanglongbing Research, Department of Plant Pathology, South China Agricultural University

\begin{abstract}
Liu, R., Zhang, P., Pu, X., Xing, X., Chen, J., and Deng, X. 2011. Analysis of a prophage gene frequency revealed population variation of 'Candidatus Liberibacter asiaticus' from two citrus-growing provinces in China. Plant Dis. 95:431-435.

Prophages are important genetic elements of bacterial genomes and are involved in lateral gene transfer, pathogenicity, environmental adaptations, and interstrain genetic variability. In this study, the sequence of a prophage terminase gene of 'Candidatus Liberibacter asiaticus', a bacterium associated with citrus Huanglongbing (HLB), was selected as a molecular marker to assess the genetic variation in two ' $\mathrm{Ca}$. $\mathrm{L}$. asiaticus' populations from geographically distinct provinces (Guangdong and Yunnan) in China. The frequency of the prophage terminase gene was $15.8 \%(19 / 120)$ in Guangdong (altitude $<500 \mathrm{~m}$ ) and $97.4 \%$

(38/39) in Yunnan (altitude $>2,000 \mathrm{~m}$ ). The difference was highly significant $(P<0.0001)$ based on $\chi^{2}$ analysis. However, the partial prophage terminase gene sequences obtained from 10 Guangdong strains and 6 Yunnan strains were identical or highly similar, suggesting that at least some bacterial strains in the two locations shared a common recent origin. This is the first report on population variation of ' $\mathrm{Ca}$. $\mathrm{L}$. asiaticus' in China, where HLB was first described. The population variation of ' $\mathrm{Ca}$. L. asiaticus' in the two geographical regions and the related HLB epidemiology were discussed.
\end{abstract}

Huanglongbing (HLB, yellow shoot disease) is a destructive disease of citrus production in China and many citrus-growing regions around the world. As of 2010, HLB occurs in 11 of the 19 citrus production provinces in China (8). Based on strong associative evidence, 'Candidatus Liberibacter asiaticus', a nonculturable $\alpha$ proteobacterium, has been commonly regarded as the pathogen of HLB (11). The Asian citrus psyllid (Diaphorina citri Kuwayama) transmits the bacterium (3). A strain of ' $\mathrm{Ca}$. Phytoplasma asteris' was recently detected in some HLB citrus in Guangdong (4). However, the role of phytoplasma in HLB etiology remains to be determined. Three other HLB-associated bacteria- ' $\mathrm{Ca}$. L. africanus' (11), 'Ca. L. americanus' (16), and a pigeon pea witches'-broom phytoplasma (17) — have not yet been reported in China.

HLB and its destructiveness were first observed in the Chaoshan area of Guangdong Province over a hundred years ago (14) and the disease is still endemic there. Because of its currently unculturable nature, ' $C a$. L. asiaticus' is usually identified based on specific DNA detection by polymerase chain reaction (PCR). Primer sets used to detect ' $\mathrm{Ca}$. L. asiaticus' were originally designed using sequences in conserved prokaryote genomic loci, mostly in the $16 \mathrm{~S}$ rRNA gene (11) and regions in the $\beta$-operon of ribosomal proteins (9). Deng et al. (6) and Tian et al. (20) first detected ' $C a$. L. asiaticus' from HLB citrus samples in Guangdong and Fujian Provinces. Subsequent research detected ' $\mathrm{Ca}$. L. asiaticus' in other citrusgrowing provinces $(10,13,21)$. HLB occurs mostly in low-altitude provinces such as Guangdong but it also occurs in the high-altitude and mountainous Yunnan Province (15,18; Fig. 1). The distinct geographical difference between Guangdong and Yunnan provides an interesting model for a comparative study of ' $\mathrm{Ca}$. L. asiaticus' population diversity.

Corresponding author: X. Deng, E-mail: xldeng@scau.edu.cn

Accepted for publication 22 November 2010.

doi:10.1094/PDIS-04-10-0300

This article is in the public domain and not copyrightable. It may be freely reprinted with customary crediting of the source. The American Phytopathological Society, 2011.
An important issue for bacterial population research is identification of appropriate molecular markers. Attempts to use primers from the $16 \mathrm{~S}$ rRNA gene and genes in the $\beta$-operon of ribosomal proteins as markers for assessing genetic variations in different ' $C a$. L. asiaticus' population were generally unsuccessful $(5,15)$. Bastianel et al. (2) used an omp-based PCR restriction fragment length polymorphism (RFLP) approach to analyze the genetic variability of ' $\mathrm{Ca}$. L. asiaticus' strains. They reported a unique RFLP profile of a single ' $\mathrm{Ca}$. L. asiaticus' strain from Yunnan. Tomimura et al. (22) performed a phylogenetic analysis using a bacteriophage-type DNA polymerase sequence and revealed three genetically distinct bacterial clusters in the Southeast Asian ' $\mathrm{Ca}$. L. asiaticus' population. In this study, we focused on a prophage gene locus and analyzed its variation in ' $\mathrm{Ca}$. L. asiaticus' populations in Guangdong and Yunnan. We further discussed the implication of prophage variation on the epidemiology of HLB and the biology of 'Ca. L. asiaticus'.

\section{Materials and Methods}

HLB sample collection. HLB-symptomatic citrus leaves were collected from Guangdong and Yunnan Provinces between July 2008 and July 2009. Each sample represented a single tree. In Guangdong, most samples were collected from the western region, where citrus is currently a major crop. Samples were also collected from the coastal eastern region, where HLB is historically endemic. In Yunnan, samples were collected from the Red River region, where citrus production is popular. All collected leaf samples were shipped by mail to the Huanglongbing Research Laboratory at the South China Agricultural University in Guangzhou. Upon arrival, the samples were stored at $4^{\circ} \mathrm{C}$ and processed within $48 \mathrm{~h}$.

DNA extraction and PCR. Total DNA was extracted from $0.2 \mathrm{~g}$ of the leaf midrib using a DNeasy Plant Mini kit (Qiagen, Valencia, CA) according to the manufacturer's instructions. The extracted DNA was stored at $-20^{\circ} \mathrm{C}$. ' $\mathrm{Ca}$. L. asiaticus' was detected by nested PCR (5). Briefly, primer set 27F (5'-AGAGTTTGA TCATGGCTCAG- $3^{\prime}$ ) and 1500 (5'-AAGGAGGTGATCCAG CCGC- $\left.3^{\prime}\right)$ was used for the first round (10 cycles) and primer set OI1 (5'-GCGCGTATCCAATACGAGCGGCA-3') and OI2c (5'GCCTCGCGACTTCGCAACCCAT-3') was used for the second round ( 35 cycles). The reaction mixture contained $2.5 \mu \mathrm{l}$ of $10 \times$ 
DNA polymerase buffer, $2.5 \mu \mathrm{l}$ of dNTPs ( $2.5 \mathrm{mM}$ each dNTP), 0.5 $\mu \mathrm{l}$ each of the forward and reverse primers $(5 \mu \mathrm{M}), 1 \mu \mathrm{l}$ of DNA template, $0.4 \mu \mathrm{l}$ of Taq DNA polymerase ( $5 \mathrm{U} / \mu \mathrm{l}$; Shanghai Shenergy Biocolor BioScience and Technology Company, PRC), and $17.6 \mu \mathrm{l}$ of double-distilled $\mathrm{H}_{2} \mathrm{O}$. An amplicon $(1 \mu \mathrm{l})$ of the first round was used as template for the second round. PCR was performed as follows: the first-round (10 cycles) reactions were preheated at $94^{\circ} \mathrm{C}$ for $5 \mathrm{~min}$; followed by the cycle of denaturation at $94^{\circ} \mathrm{C}$ for $30 \mathrm{~s}$, annealing at $50^{\circ} \mathrm{C}$ for $30 \mathrm{~s}$, and extension at $72^{\circ} \mathrm{C}$ for $90 \mathrm{~s}$. The second-round (35 cycles) reactions were preheated at $96^{\circ} \mathrm{C}$ for $1 \mathrm{~min}$; followed by the cycle of denaturation at $94^{\circ} \mathrm{C}$ for $30 \mathrm{~s}$, annealing at $55^{\circ} \mathrm{C}$ for $30 \mathrm{~s}$, and extension at $72^{\circ} \mathrm{C}$ for $60 \mathrm{~s}$; with a final extension at $72^{\circ} \mathrm{C}$ for 4 min. Amplicons were evaluated by electrophoresis in $1 \%$ agarose gels and visualized by staining with Goldview (GeneShun Biotech Ltd., Guangzhou, China).

The prophage gene was detected by PCR with primer set $766 \mathrm{~F}$ (5'-CAATAACAGGACCTCTACGC-3') and 766R (5'-ATTGGA AAGACGACGTTAAA- $3^{\prime}$ ), designed based on the sequence of gene CLIBASIA_05610 in the genome of ' $\mathrm{Ca}$. L. asiaticus' strain Psy62 (7). This genomic locus was annotated as encoding a phage terminase. For the convenience of discussion in this article, we also used this gene to represent the corresponding prophage. The reaction mixture was the same as above. DNA amplification by PCR was performed as follows: reactions were preheated at $94^{\circ} \mathrm{C}$ for 5 min; followed by 35 cycles of denaturation at $94^{\circ} \mathrm{C}$ for $30 \mathrm{~s}$, annealing at $55^{\circ} \mathrm{C}$ for $30 \mathrm{~s}$, and extension at $72^{\circ} \mathrm{C}$ for $90 \mathrm{~s}$; with a final extension at $72^{\circ} \mathrm{C}$ for $7 \mathrm{~min}$. Amplification products were evaluated by electrophoresis in $1 \%$ agarose gels and visualized by staining with Goldview.

Sequence and statistical analyses. Selected PCR amplicons were cloned in plasmid pMD18-T and sequenced (Shanghai Bioasia Biology and Technology Company, Shanghai, China; AuGCT Biotechnology Company, Beijing). DNA sequences were compared with the current GenBank database using the BLASTn and BLASTx network service available in the National Center for Biotechnology Information (1). Multiple sequence alignments and bacterial strain phylograms were generated using CLUSTAL W (19). Due to high sequence identity, the sequence of strain YN-840 was selected to represent all China strains for BLASTx search. The sequence of YN-840 had been deposited in GenBank with an accession number of HM105498. Prophage gene frequency data were analyzed using a $\chi^{2}$ test with Statistical Analysis System 8.1 (24)

\section{Results}

The provincial map along with geographical information is summarized in Figure1. In Yunnan, the counties of Huaning, Jianshui, and Gejiu are located in the southeastern part of the province and are part of the Yunnan-Guizhou Plateau, with a mean elevation of $>2,000 \mathrm{~m}$. It has a plateau monsoon climate with a mean annual temperature of 15 to $18^{\circ} \mathrm{C}$. Mean annual precipitation is $1,100 \mathrm{~mm}$ in Gejiu and 700 to $800 \mathrm{~mm}$ in Huaning and Jianshui. The climate in Guangdong is divided into a subtropical zone that includes Zhaoqing, Luoding, Yuncheng, Yunan, and Qingyuan; and a subtropical monsoon zone that includes Xinhui, Chaozhou, Zeng-

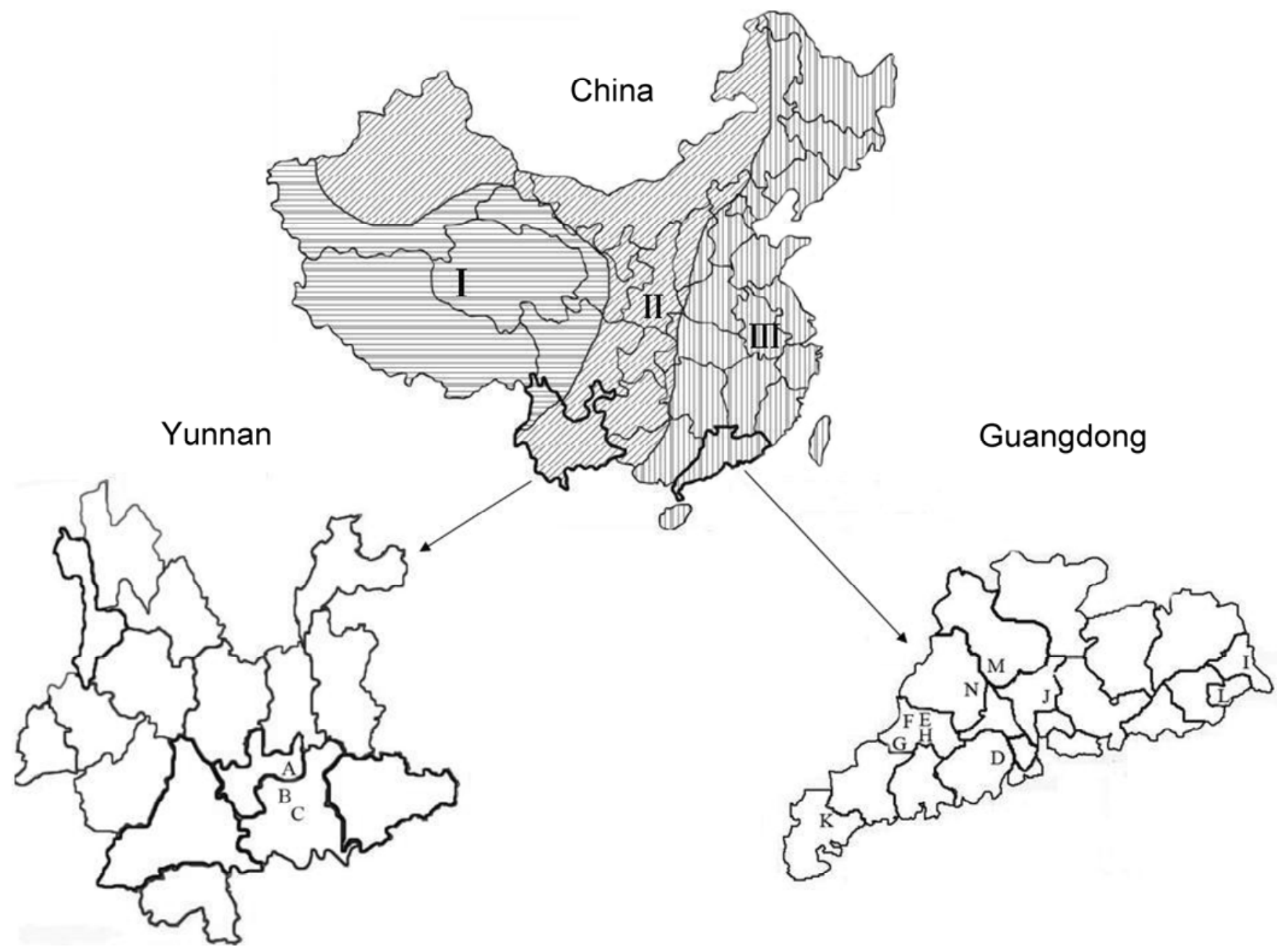

Fig. 1. Geographical locations in Guangdong and Yunnan Provinces of the People's Republic of China, where citrus Huanglongbing samples were collected in this study. Codes for altitude: I, >4,000 m; II, 500-4,000 m; and III, <500 m. Alphabet codes for locations: A, Huaning; B, Jianshui; C, Gejiu; D, Xinhui; E, Yun'an; F, Yu'nan; G, Luoding; H, Yuncheng; I, Chaozhou; J, Zengcheng; K, Lianjiang; L, Shantou; M, Qingyuan; and N, Zhaoging. 
cheng, Shantou, and Lianjiang. Citrus is mainly cultivated in the hilly areas in Guangdong with a mean elevation of $<500 \mathrm{~m}$ and a mean annual precipitation of 1,500 to $2,000 \mathrm{~mm}$. The mean annual temperature is 19 to $23^{\circ} \mathrm{C}$.

Detection of ' $\mathrm{Ca}$. L. asiaticus' was based on PCR amplification of an expected approximately 1,167-bp DNA amplicon with primer set OI1/OI2c and nested with primer set 27F/1500R (Fig. 2A and $\mathrm{B})$. The prophage terminase gene (representing the corresponding prophage) was indicated by the expected approximately 766-bp DNA amplicon with primer set 766f/766r (Fig. 2A and B). The prophage gene was detected only in DNA samples prepared from trees infected with ' $\mathrm{Ca}$. L. asiaticus'. In Guangdong Province, ' $\mathrm{Ca}$. L. asiaticus' was detected in $120(77.9 \%)$ of the 154 citrus DNA samples from 11 cities. The prophage gene was detected in 19 $(15.8 \%)$ of these samples (Fig. 2A). 'Ca. L. asiaticus' was detected

A

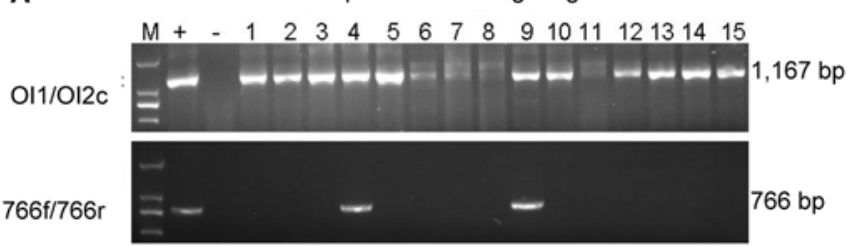

B

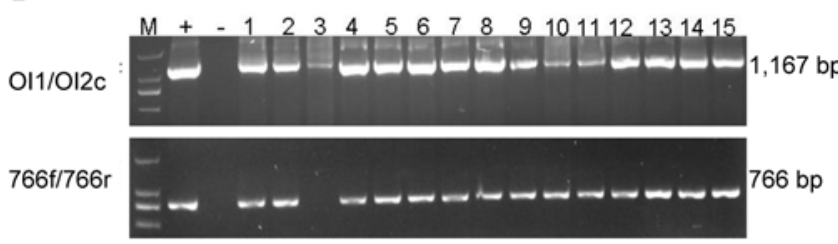

Fig. 2. Summary of polymerase chain reaction detections of 'Candidatus Liberibacter asiaticus' represented by the 16S rRNA gene and a prophage represented by a phage terminase gene (CLIBASIA_05610) in samples from A, Guangdong and $\mathbf{B}$, Yunnan. $\mathrm{M}$, molecular markers in kilobases (from top to bottom): 2,000, 1,000, 750, and 500; + = positive control, with DNA sample GD544 known to be positive for ' $\mathrm{Ca}$. L. asiaticus' and CLIBASIA_05610 base on previous tests; - = negative control, with distilled water. in $39(88.6 \%)$ of the 44 citrus DNA samples from three counties in Yunnan Province and the prophage gene was detected in 38 (97.4\%) of the 39 ' $\mathrm{Ca}$. L. asiaticus'-positive DNA samples (Fig. 2B). PCR detection on ' $\mathrm{Ca}$. L. asiaticus' and the prophage frequencies are summarized in Table 1 . Based on $\chi^{2}$ analysis, the detection frequencies of ' $\mathrm{Ca}$. L. asiaticus' between Guangdong and Yunnan were not significantly different $(P=0.1150)$. However, the detection frequencies of prophage between the two provinces were significantly different $(P<0.0001)$. The Guangdong ' $\mathrm{Ca}$. L. asiaticus' population had a significantly lower frequency of the prophage than the population in Yunnan.

Nucleotide sequences of 10 Guangdong and 6 Yunnan prophage amplicons were very similar, with a few randomly distributed single-nucleotide polymorphisms (data not shown). As expected, a BLASTn search matched all the Guangdong and Yunnan sequences with the phage terminase gene (CLIBASIA_05610) of ' $C a$. L asiaticus' strain Psy62 in Florida. A phylogram derived from the results of sequence comparison of all ' $\mathrm{Ca}$. L. asiaticus' prophage genes is shown in Figure 3. All China strains were closely related, with a distance less than 0.004 , whereas the Florida strain had a distance of 0.013 .

A BLASTx search with YN-840 identified 61 similar amino acid sequences of bacterial prophage or phage origins, including both gram-positive and -negative bacteria. Among them, 35 had query coverage $>90 \%$, with max identity ranging from 24 to $98 \%$. Query coverage and max identity are two parameters of BLASTx result descriptions. Query coverage describes the comparable length of two sequences and max identity describes the number of identical amino acid matches. In addition to YP003065628, the putative gene product of CLIBASIA_05610 (query coverage $=99 \%$ and max identity $=98 \%$ ), another amino acid sequence, YP003065600, encoded by CLIBASIA_05470, was identified in the same bacterial genome, with $99 \%$ query coverage and $76 \%$ max identity. CLIBASIA_05470 was also annotated as a phage terminase gene. Among the 35 BLASTx matches were two bacteriophages, Enterobacteria phage epsilon15 (NP_848210.1) and Escherichia phage phiV10 (YP_512256.1), sharing 32\% max identity over 98\% query coverage and $31 \%$ max identity over $98 \%$ query coverage, respectively. Both phages are members of the Podoviridae family and capable of integrating into their host bacterial chromosomes (12). Interestingly, although prophages were present in members of the

Table 1. Summary of geographical locations, host information, and polymerase chain reaction (PCR) detection of 'Candidatus Liberibacter asiaticus' and a prophage from samples collected from various citrus plants with Huanglongbing symptoms

\begin{tabular}{|c|c|c|c|c|c|}
\hline \multirow[b]{2}{*}{ Geographical origin } & \multirow[b]{2}{*}{ Host species } & \multirow[b]{2}{*}{ Cultivar } & \multirow[b]{2}{*}{ Total sample } & \multicolumn{2}{|c|}{ PCR detection $(\%)^{\mathrm{a}}$} \\
\hline & & & & 'Ca. L. asiaticus' & Prophage \\
\hline \multicolumn{6}{|l|}{ Yunnan Province } \\
\hline A, Huaning & Citrus unshiu Marc. & Wenzhoumigan & 4 & 1 & 1 \\
\hline \multirow[t]{3}{*}{ B, Jianshui } & C. reticulata Blanco & Jiaogan & 25 & 25 & 25 \\
\hline & C. medica $\mathrm{L}$. & Xiangyuan & 1 & 1 & 1 \\
\hline & C. maxima (Burm.) Merr. & Youzi & 2 & 2 & 1 \\
\hline C, Gejiu & C. reticulata Blanco & Jiaogan & 12 & 10 & 10 \\
\hline Subtotal $(n=3)$ & $\ldots$ & $\ldots$ & 44 & $39(88.6)$ & $38(97.4)$ \\
\hline \multicolumn{6}{|l|}{ Guangdong Province } \\
\hline \multirow[t]{2}{*}{ D, Xinhui } & C. limon (L.) Burm. f. & Hongningmeng & 5 & 2 & 0 \\
\hline & C. reticulata Blanco & Chazhigan & 2 & 0 & 0 \\
\hline E, Yun'an & C. reticulata Blanco & Shatangju & 6 & 6 & 1 \\
\hline F, Yu'nan & C. reticulata Blanco & Shatangju & 15 & 11 & 2 \\
\hline G, Luoding & C. reticulata Blanco & Shatangju & 17 & 12 & 0 \\
\hline $\mathrm{H}$, Yuncheng & C. reticulata Blanco & Shatangju & 15 & 15 & 4 \\
\hline \multirow[t]{2}{*}{ I, Chaozhou } & C. sinensis Hayata & Xuecheng & 1 & 1 & 0 \\
\hline & C. medica $\mathrm{L}$. & Foshou & 1 & 1 & 1 \\
\hline J, Zengcheng & C. reticulata Blanco & Shatangju & 8 & 2 & 0 \\
\hline $\mathrm{K}$, Lianjiang & C. sinensis (L.) Osbeck. & Hongjiangcheng & 5 & 5 & 0 \\
\hline L, Shantou & C. reticulata Blanco & Jiaogan & 2 & 2 & 0 \\
\hline M, Qingyuan & C. reticulata Blanco & Shatangju & $4 \overline{3}$ & 39 & 11 \\
\hline $\mathrm{N}$, Zhaoqing & C. reticulata Blanco & Shatangju & 34 & 24 & 0 \\
\hline Subtotal $(n=11)$ & $\ldots$ & $\ldots$ & 154 & $120(77.9)$ & $19(15.8)$ \\
\hline Total $(n=14)$ & $\ldots$ & $\ldots$ & 198 & $159(80.3)$ & $57(35.9)$ \\
\hline
\end{tabular}

${ }^{a}$ Numbers in parentheses are percent detection rate. 'Ca. L. asiaticus' was represented by the 16S rRNA gene and prophage was represented by prophage terminase gene CLIBASIA_05610. 
Rhizobiaceae family, which is phylogenetically close to ' $\mathrm{Ca}$. L. asiaticus', none showed significant similarity to the terminase gene of ' $C a$. L. asiaticus' in this study.

\section{Discussion}

At least two reports have been published on the utilization of prophage gene sequences to study strain diversity of ' $\mathrm{Ca}$. L. asiaticus' $(22,23)$. These researchers described and analyzed the sequence variation of a phage DNA polymerase gene from different geographical sources. With the phage terminase gene, we note that the Guangdong and Yunnan strains are highly similar or identical and, therefore, these strains shared a common recent origin. In contrast, the Florida strain is much further apart because its genetic distance is three times longer than those within the China strains. Because only a single Florida strain was compared, it will be necessary in the future to include more Florida strains for a comprehensive phylogenetic evaluation.

Although Yunnan Province is one of the geographic origins of citrus, neither HLB nor the Asian citrus psyllid was found and reported there until the 1970s $(18,25)$. The current hypothesis proposes that HLB in Yunnan was introduced from Guangdong. This has been mainly supported by records of citrus cultivar introductions. Zeng (25) described a record that citrus seedlings were introduced into Eshan City, which is less than $150 \mathrm{~km}$ from the locations where we collected the HLB samples for this study, from Guangdong in 1968, and an HLB outbreak was reported in 1979 along with observations of citrus psyllids in densities ranging from 5 to 37.5 per leaf. The sequence identity of the partial phage terminase gene in the two provinces provides molecular evidence for the hypothesis of the Guangdong origin of ' $\mathrm{Ca}$. L. asiaticus'.

Based on an omp gene sequence, Bastianel et al. (2) studied a single Yunnan strain of ' $\mathrm{Ca}$. L. asiaticus' from an unspecified location and showed that it had a unique RFLP profile compared with other strains from different geographical sources, including a strain from Beihai, a city of Guangxi Province on the western border of Guangdong. However, it is not known how representative this Yunnan strain was. In this study, 39 Yunnan strains from three different citrus-growing counties were analyzed. Our results showed that the Yunnan population of ' $\mathrm{Ca}$. L. asiaticus' was different from that in Guangdong. Rather than nucleotide sequence variation, the difference between the two geographical regions was in the frequencies of a prophage occurrence. It has been speculated that high-altitude areas are associated with lack or slower development of HLB, probably due to the effect on Asian citrus psyllid (26). It is also tempting to link the altitude difference (as well as climate and other ecological factors) between Guangdong and Yunnan to the difference in prophage frequency or ' $\mathrm{Ca}$. L. asiaticus' populations. However, direct evidence of cause and effect is currently lacking. A more plausible explanation is genetic drift in the evolution of the two ' $\mathrm{Ca}$. L. asiaticus' populations due to their geographical separation over an estimated period of 30 to 40 years.

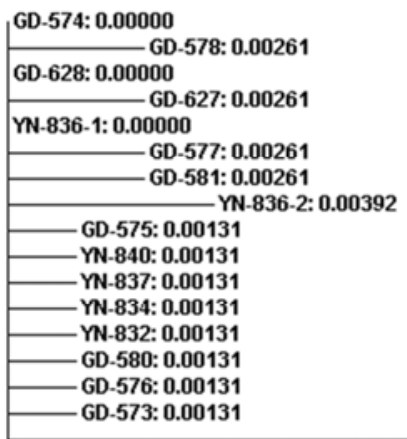

Fig. 3. Unrooted phylogram, derived from CLUSTAL $W$ alignment of partial sequences of a phage terminase gene (CLIBASIA_05610), illustrating the genetic distance (numbers after columns) among 'Candidatus Liberibacter asiaticus' strains from Guangdong and Yunnan Provinces of China and Florida of the United States.
Currently, no information is available regarding the biology of prophages or phages in ' $\mathrm{Ca}$. L. asiaticus'. In the whole-genome sequence annotation of ' $\mathrm{Ca}$. L. asiaticus' strain Psy62 (7), at least 16 open reading frames (ORFs) upstream (starting at CLIBASIA_05530) and 13 ORFs downstream (ending at CLIBASIA_05675) of CLIBASIA_05610 are putative genes coding for phage-associated proteins or hypothetical proteins. The 30gene sequence is large enough to possibly be a complete prophage. The presence and absence of the prophage gene adds direct evidence that the prophage is capable of being lytic and lysogenic, although further experimental proofs are needed.

\section{Acknowledgments}

We thank L. Wu, W. Shen, and Y. Liu for their technical assistance. Part of this research was supported by Guangdong Provincial Foundation of Natural Sciences and Special Research Programs of Plant Quarantine of Guangdong, P. R. China.

\section{Literature Cited}

1. Altschul, S. F., Gish, W., Miller, W., Myers, E. W., and Lipman, D. J. 1990 Basic local alignment search tool. J. Mol. Biol. 215:403-410.

2. Bastianel, C., Garnier-Semancik, M., Renaudin, J., Bove, J. M., and Eveillard, S. 2005. Diversity of 'Candidatus Liberibacter asiaticus', based on the omp gene sequence. Appl. Environ. Microbiol. 71:6473-6478.

3. Bove, J. M. 2006. Huanglongbing: a destructive, newly-emerging, centuryold disease of citrus. J. Plant Pathol. 88:7-37.

4. Chen, J., Pu, X., Deng, X., Liu, S., Li, H., and Civerolo, E. 2009. A phytoplasma related to 'Candidatus Phytoplasma asteris' detected in citrus showing Huanglongbing (yellow shoot disease) symptoms in Guangdong, P. R China. Phytopathology 99:236-242.

5. Deng, X., Chen, J., Feng, Z., Shan, Z., Guo, H., Zhu, J., Li, H., and Civerolo, E. L. 2008. Identification and characterization of the Huanglongbing bacterium in pummelo from multiple locations in Guangdong, P. R. China. Plant Dis. 92:513-518.

6. Deng, X. L., and Tang, W. W. 1996. The studies on detection of citrus Huanglongbing pathogen by polymerase chain reaction. J. South China Agric. Univ. 17:119-120.

7. Duan, Y. P., Zhou, L. J., Hall, D. G., Li, W. B., Doddapaneni, H., Lin, H., Liu, L., Vahling, C. M., Gabriel, D. W., Williams, K. P., Dickerman, A., Sun, Y. J., and Gottwald, T. 2009 Complete genome sequence of citrus Huanglongbing bacterium, 'Candidatus Liberibacter asiaticus' obtained through metagenomics. Mol. Plant-Microbe Interact. 22:1011-1020.

8. Fan, G. C., Liu, B., Wu, R. J., Li T, Cai, Z. J., and Ke, C. 2009. Thirty years of research on citrus Huanglongbing in China. Fujian J. Agric. Sci. 24:183-190.

9. Hocquellet, A., Toorawa, P., Bove, J. M., and Garnier, M. 1999. Detection and identification of the two Candidatus Liberibacter species associated with citrus huanglongbing by PCR amplification of ribosomal protein genes of the beta operon. Mol. Cell. Probes 13:373-379.

10. Hu, H., Yin, Y. P., Zhang, L. P., Zhao, Y., Xia, Y. X., Wang, Z. K., and Tan, J. 2006. Detection of citrus Huanglongbing by conventional and two fluorescence quantitative PCR assays. Sci. Agric. Sin. 39:2491-2497.

11. Jagoueix, S., Bove, J. M., and Garnier, M. 1994. The phloem-limited bacterium of greening disease of citrus is a member of the alpha subdivision of the Proteobacteria. Int. J. Syst. Bacteriol. 44:379-386.

12. Kropinski, A. M., Kovalyova, I. V., Billington, S. J., Patrick, A. N., Butts, B. D., Guichard, J. A., Pitcher, T. J., Guthrie, C. C., Sydlaske, A. D., Barnhill, L. M., Havens, K. A., Day, K. R., Falk, D. R., and McConnell, M. R. 2007. The genome of 15, a serotype-converting, group E1 Salmonella entericaspecific bacteriophage. Virology 369:234-244.

13. Liao, X. L., Zhu, S. F., Zhao, W. J., Luo, K., Qi, Y. X., Chen, H. Y., He, K., and Zhu, X. X. 2004. Cloning and sequencing of citrus Huanglongbing pathogen 16S rDNA and its detection by real-time fluorescent PCR. J. Agric. Biotechnol. 12:80-85

14. Lin, K. S. 1956 Observations on yellow shoot of citrus. Acta Phytopathol. Sin. 2:1-11.

15. Shan, Z. J., Feng, Z., Zhou, G., and Deng, X. L. 2008. Cloning and sequence analysis of $16 \mathrm{~S}$ rDNA of citrus Huanglongbing agents collected from five provinces in South China. J. South China Agric. Univ. 29:25-29.

16. Teixeira, D. C., Saillard, C., Eveillard, S., Danet, J. L., da Costa, P. I., Ayres, A. J., and Bove, J. 2005 'Candidatus Liberibacter americanus,' associated with citrus huanglongbing (greening disease) in Sao Paulo State, Brazil. Int. J. Syst. Evol. Microbiol. 55:1857-1862.

17. Teixeira, D. C., Wulff, N. A., Martins, E. C., Kitajima, E. W., Bassanezi, R., Ayres, A. J., Eveillard, S., Saillard, C., and Bove, J. M. 2008. A phytoplasma closely related to the pigeon pea witches'-broom phytoplasma(16Sr IX) is associated with citrus huanglongbing symptoms in the state of São Paulo, Brazil. Phytopathology 98:977-984.

18. The Citrus Huanglongbing Research Group of Yunnan Province. 1981. The report of yellow shoot disease in Yunnan Province. South China Fruits 4:1416

19. Thompson, J. D., Higgins, D. G., and Gibson, T. J. 1994. CLUSTAL W: 
improving the sensitivity of progressive multiple sequence alignment through sequence weighting, position-specific gap penalties and weight matrix choice. Nucleic Acids Res. 22:4673-4680.

20. Tian, Y. N., Ke, S., and Ke, C. 1996. Detection and quantitation of citrus Huanglongbing pathogen by polymerase chain reaction. Acta Phytopathol. Sin. 26:243-250

21. Tian, Y. N., Ke, S., Li, T., Xu, P. D., and Ke, C. 2000. Detection of Huanglongbing pathogen in Guanximiyou pomelo by electron microscopy and PCR analysis. Acta Phytopathol. Sin. 30:76-81.

22. Tomimura, K., Miyata, S. I., Furuya, N., Kubota, K., Okuda, M., Subandiyah, S., Hung, T. H., Su, H. J., and Iwanami, T. 2009. Evaluation of genetic diversity among 'Candidatus Liberibacter asiaticus' isolates collected in
Southeast Asia. Phytopathology 99:1062-1069.

23. Villechanoux, S., Garnier, M., Laigret, F., Renaudin, J., Bove, J. M. 1993. The genome of the non-cultured, bacterial-like organism associated with citrus greening disease contains the nusG-rplKAJL-rpoBC ene cluster and the gene for a bacteriophage type DNA polymerase. Curr. Microbiol. 26:161-166.

24. Wang, H. Q., and Li, Y. H. 2002. Pages 9-83 in: SAS Program Design. Science Press.

25. Zeng, L. D. 1993. Analysis on the causes of popularity of citrus yellow shoot (CYS). J. Yunnan Agric. Univ. 3:286-287.

26. Zhao, X.-Y. 1981. Citrus yellow shoot disease (huanglongbing) in China-a review. Proc. Int. Soc. Citric. 1:466-469. 